\title{
Derechos humanos y democracia: Habermas, Rorty, Rawls y Forst
}

\author{
Human rights and democracy: Habermas, Rorty, Rawls and Forst
}

\begin{abstract}
Nicholas Dieter Berdaguer Rauschenberg nicholasrauschenberg@yahoo.com.br http://orcid.org/0000-0002-1779-0622

Instituto de Estudios para América Latina y el Caribe; Facultad de Ciencias Sociales; Universidad de Buenos Aires/ Consejo Nacional de Investigaciones Científicas y Técnicas (Argentina)
\end{abstract}

\section{Resumen}

En el contexto de la Teoría Crítica de la Sociedad, abordaremos en el presente artículo la relación entre democracia y derechos humanos. ¿Es posible argumentar epistemológicamente a favor de la democracia? ¿O, antes, tendríamos que reconocer la dimensión dialéctica de la democracia? Veremos que Habermas sostiene que los derechos humanos y la soberanía popular son cooriginarios, pero en el marco de una filosofía del lenguaje y no como ontología. Así, a partir de los debates que Habermas tuvo con Richard Rorty y John Rawls, el principio del discurso será entendido como principio de justificación para la democracia. Reconstruiremos el pensamiento de Rainer Forst sobre la noción de justificación y su rol en el constructivismo moral y político de los derechos humanos. Finalmente, analizaremos brevemente dos controversias sobre la teoría de los derechos humanos presentes en Menke y Pollman. La 
primera se refiere a la oposición entre la concepción moral y la concepción política de los derechos humanos. Y la segunda aborda la oposición dialéctica entre una comprensión maximalista y otra minimalista de los derechos fundamentales y su relación con la construcción política.

Palabras clave: Derechos Humanos; Jürgen Habermas; Rainer Forst; democracia.

\section{Abstract}

In the context of the Critical Theory of Society, we will address in this article the relationship between democracy and human rights. Is it possible to argue epistemologically in favor of democracy? Or, rather, should we recognize the dialectical dimension of democracy? We will see that Habermas argues that human rights and popular sovereignty are cooriginal, but within the framework of a philosophy of language and not as ontology. Thus, from Habermas's discussions with Richard Rorty and John Rawls, the principle of discourse will be understood as the principle of justification for democracy. We will then reconstruct Rainer Forst's thinking on the notion of justification and its role in the moral and political constructivism of human rights. Finally, we will briefly discuss two controversies on the theory of human rights present in Menke and Pollman. The first refers to the opposition between the moral conception and the political conception of human rights. And the second deals with the dialectical opposition between a maximalist and a minimalist understanding of fundamental rights and their relation to political construction.

Keywords: Human Rights; Jürgen Habermas; Rainer Forst; democracy.

¿Qué relaciones formales tienen democracia y derechos humanos? Teniendo en cuenta el horizonte dialéctico de la democracia, buscaremos en este artículo reconstruir el vínculo entre democracia y derechos humanos a partir de algunos debates intelectuales donde se destaca Jürgen Habermas. En primer lugar, el debate con Richard Rorty tiene un rasgo propiamente epistemológico. Aquí Habermas buscará defender que el principio de democracia basado en el principio del discurso es un presupuesto de los usos del lenguaje y no fruto de una "racionalidad", como acusa Rorty al llevar la discusión al ambiguo suelo del "culturalismo", por así decirlo. En seguida analizaremos el debate entre Habermas y John Rawls buscando deconstruir la supuesta preeminencia que el liberalismo tendría en relación a la democracia. 
Sostendremos con Habermas que los derechos humanos son cooriginarios a la soberanía popular en la medida que están en movimiento generando disputas y nuevos contextos políticodiscursivos. Una vez presentada la dimensión dialéctica de la democracia discursiva nos detenemos en el planteo de Rainer Forst, discípulo de Habermas, en torno a la noción de justificación como un principio básico de los derechos humanos en el camino de una reconstrucción democrática. El constructivismo de Forst articula las justificaciones situadas socialmente del derecho, de la política y de la moral para pensar parámetros de crítica inmanente y trascendente a la vez. Finalmente, ya a modo de excurso, nos detendremos, como variante de las discusiones anteriores, en dos controversias en torno a la articulación dialéctica entre política y moral de los derechos humanos discutidas por Christoph Menke y Arnd Pollmann.

\section{Etnocentrismo y procedimentalismo democrático}

Ante el énfasis habermasiano en la noción de racionalidad, Richard Rorty (1996: 243) propone una trampa conceptual, por así decirlo, al sobreponer racionalidad y verdad: ¿Necesita una política democrática estar respaldada -ser justificada- por una teoría de la verdad? En su argumentación irónica, Rorty "redescribe" una premisa del pensamiento de Habermas: "se dice que el surgimiento de sociedades relativamente democráticas y tolerantes en los siglos recientes se debe a la mayor racionalidad de los tiempos modernos, donde 'racionalidad' denota empleo de una facultad innata orientada a la verdad" (2000: 80). Para Rorty esa "verdad" como elemento de la "racionalidad" debería ser entendida en realidad como justificación. Alguna cadena de proposiciones puede estar justificada, pero no necesariamente será verdadera (Ibídem: 87). Así, "describir el discurso y la comunicación en términos que hacen que la democracia parezca vinculada con la naturaleza intrínseca de la humanidad" (Ídem), no sería más que imponer un estatus de "verdadero" a una justificación cuyas premisas y proposiciones estarían validadas por una selección de aspectos de la realidad histórica y de la historia de la filosofía. Rorty retoma a John Rawls para argumentar en favor de la prioridad de la democracia ante la filosofía. "Rawls desvincula el problema de si debemos ser tolerantes y socráticos del de si esta estrategia nos conducirá o no a la verdad" (Rorty, 1996: 261). Mientras que la democracia liberal se muestra casi como una circunstancia histórica y, así, contextualizable, la filosofía debería contener su ímpetu de justificar cierta verdad política a partir de una teoría del "yo" o de la "esencia humana". Según Rorty, es el "nosotros" de la democracia liberal concreta que permite poner la libertad - tolerancia religiosa y gobierno 
constitucional - por encima de la perfección (Rorty, 1996: 253). Por lo tanto, de acuerdo con Rorty, para pensar y defender la democracia liberal hay que recurrir a la estrategia holista: contextualista y etnocéntrica. Nuevamente retomando a Rawls, Rorty defiende la necesidad de insistir en que no hay un más allá del "equilibrio reflexivo", es decir, que "no hay ningún orden natural de justificación de las creencias, ningún esquema preestablecido para el argumento" (Rorty, 1996: 263).

Sin embargo, si asumimos que el representacionismo (contextualista) se vincula al paradigma de la filosofía del sujeto (o "mentalista"), por otro lado, en una perspectiva postmetafísica, es decir, en el paradigma lingüístico en el cual Habermas se basa, el coherentismo epistemológico parece ofrecer una interpretación más consistente de lo que está en juego en la obra de Habermas (y sus transformaciones) que el contextualismo etnocéntrico de Rorty. El coherentismo rechaza el presupuesto de que la justificación deba necesariamente vincularse a la linealidad (Bonjour, 1986). La metáfora de la justificación como una cadena compuesta por eslabones doxásticos parece imponerse con naturalidad en razón de cómo el problema del regreso epistémico es presentado: cada proposición justificaría la siguiente proposición. Por eso parece plausible en la argumentación de Rorty que sólo pueda haber validez si hay una debida justificación muy bien contextualizada, es decir, concatenada en proposiciones lógicas. No obstante, una cadena doxástica no necesita tener únicamente ese tipo de vínculo proposicional para ser validada (Burdzinski, 2005: 76). Hay que asumir puntos de vista distintos y complementarios. Si, por un lado, nos restringimos a la linealidad, la fuerza de la cadena justificadora no sobrepasa el más débil de sus eslabones. Pero si, por otro lado, consideramos el modo sistémico de justificación, la fuerza de la cadena justificadora debe evaluarse desde la combinatoria de sus eslabones. En contextos ordinarios la justificación aparece invariablemente como lineal: "justificamos nuestras creencias particulares a partir de otras creencias particulares" (Ibídem: 80). Para evitar una circularidad viciosa en que recae la estricta linealidad, la justificación sistémica debe ser entendida como global y fragmentada a la vez a partir de las relaciones complejas de interdependencia y complementariedad de sus proposiciones o fragmentos de cadenas proposicionales. Por lo tanto, si tomamos la justificación epistémica en su carácter global y disperso en vez de en su carácter local y concentrado, "deja de ser razonable pensar en un sistema doxástico como una única larga serie de creencias linealmente conectadas" (Ibídem: 79). La reconstrucción de la democracia deliberativa de Habermas busca valerse de una justificación sistémica al apoyarse tanto en la tradición liberal (autonomía privada, libertad de los modernos, derechos del hombre, etcétera) como en la que considera republicana (autonomía pública, libertad de los antiguos, soberanía popular, etcétera). 
$\mathrm{Si}$, por un lado, la redescripción de la problemática habermasiana planteada por Rorty busca romper una cadena de inferencias doxásticas, por otro, dado el efecto de perplejidad de esa ruptura, Rorty propone una nueva cadena doxástica basada en una circularidad viciosa: racionalidad y democracia no tendrían causalidad entre sí, sino una justificación en "lo político". Rawls no estaría en desacuerdo porque sostiene que su teoría del liberalismo político no es metafísica, sino política. Habermas, antes, parece estar preocupado en comprender cómo la coherencia puede producir justificación de una manera no necesariamente inferencial y lineal. El modo de circularidad (no viciosa) presente en la teoría de Habermas debe ser entendido desde su estructura conceptual debido a la superposición de creencias y resortes normativos que presuponen distintos niveles de justificación (arte, moral, derecho, derecho internacional, ética), lo que evita el exacerbado contextualismo de Rorty, orientado a descartar la noción de verdad "independiente del contexto" en favor de una limitada cadena de proposiciones justificables. Rorty elimina, de este modo, el concepto de verdad en favor de una validez-paranosotros epistémica, dependiente muy estrechamente del contexto, lo que lo hace "perder el punto de referencia normativo necesario para explicar por qué un proponente debe esforzarse por buscar un acuerdo para ' $p$ ' más allá de los límites de su propio grupo" de validez epistémica (Habermas, 2007: 257). Lo que Habermas argumenta ante el contextualismo de Rorty es que éste no es capaz de distinguir entre usos estratégicos y no estratégicos del lenguaje, entre la acción orientada hacia el éxito y la acción orientada hacia el logro del entendimiento, entre convencer y persuadir, entre aprendizaje y adoctrinamiento. Al reemplazar la "correcta descripción de los hechos" por la "adaptación exitosa al entorno", Rorty no hace más que intercambiar una clase de objetividad por otra: "el objetivismo de la realidad 'representada' por el objetivismo de la realidad 'dominada' instrumentalmente" (Ibídem: 258). El "uso precautorio" (cautionary use) del lenguaje apunta a una pretensión de verdad que apela inevitablemente a lo incondicional: es inmanente al contexto, al mismo tiempo que lo sobrepasa. Esa pretensión de verdad traspasa los contextos de justificación a la vez que los presupone necesariamente. Habermas apunta a una necesaria relación entre verdad y justificación: la verdad no puede ser reducida a la asertividad justificada. La justificación es, en su relación dialéctica y complementaria con la verdad, "una cuestión de sustentar creencias mediante otras creencias y, por ende, en su sentido mínimo, una cuestión de coherencia" (Ibídem: 239).

\section{Liberalismo y democracia discursiva}


El problema de la relación entre verdad y justificación nos lleva a la pregunta por el lugar epistemológico de los derechos humanos en el planteo de Habermas: como principio de justificación, los derechos humanos son la base del derecho liberal al que Habermas le vincula el concepto de soberanía popular como vínculo inmanente y condición de posibilidad para la legitimación democrática. Sin embargo, Rorty podría afirmar que los derechos humanos no son más que un conjunto de principios morales que buscan, en el interior de una comunidad, adquirir validez jurídica y, si posible, validez también más allá de esa comunidad. Pero no todos los modelos teórico-políticos tienen problematizada la "metadiscursividad" que implica su teoría. Un ejemplo de ello es John Rawls, que no consigue romper el encanto de un nuevo contractualismo en el marco de una argumentación político-moralista acerca de los derechos. La "justicia como equidad" produce una concepción política de justicia para un régimen democrático que puede ser aceptado por todas las doctrinas "razonables" existentes enmarcadas en una sociedad democrática "bien ordenada". El overlaping consensus es un modelo demasiado reconciliador para pensar las diferencias y los intereses sociales porque no piensa desde las instituciones qué hacer con las diferencias en juego. Habermas (2010) busca institucionalizar el uso "público de la razón" para validar desde la esfera pública los discursos y demandas político-sociales relevantes, mientras que las instituciones para Rawls deben resguardarse al orden constitucional preestablecido. En su modelo instrumentalista del liberalismo político, los principios de justicia aparecen como fundamentos apenas políticos de una teoría normativa vaciada de historicidad y expectativas de emancipación. Su perspectiva práctica se limita, por tanto, a cómo los actores sociales se valen de sus principios de neutralidad y justificación de diferencias razonables en la diversidad de doctrinas. La idea de la posición original es apenas un "mecanismo de representación" que sirve como medio hipotético de reflexión pública (Rawls, 2006: 56). Si Habermas buscaba en la "situación ideal de habla" una situación ideal neutral libre de distorsiones semánticas -lo que llamamos "principio de justificación discursivo"-, la posición original rawlsiana remite a un principio de justificación restringido a una neutralidad político-moral. Esa neutralidad deriva de lo "razonable" que puede ser una doctrina específica ante las otras doctrinas en el equilibrio reflexivo y en el consenso sobrepuesto (overlaping). El así llamado equilibrio reflexivo de John Rawls busca acercarse de cierto modo al test del discurso ideal o situación ideal de habla, ya que es un punto o idea reguladora que, en efecto, nunca se puede alcanzar definitivamente. Es posible aproximarse de este equilibrio cuando, a través de las discusiones, los principios del juicio en cuestión parezcan más razonables y sean considerados mejor fundamentados que antes de la conversación. 
Recordemos que, con la noción de consenso entrecruzado, Rawls busca "un consenso entre doctrinas comprehensivas razonables (no irrazonables o irracionales). El hecho crucial no es el hecho del pluralismo como tal, sino el del pluralismo razonable" (Rawls, 2006: 176). Antes que entrar en un debate en torno de una idea de verdad, Rawls sostiene que el término "razonable" expresa una actitud reflexiva en relación a la tolerancia, mientras que la noción de verdad pertenece a la disputa entre las amplias y distintas doctrinas que buscan legitimarse en un escenario político ya demarcado por las reglas del liberalismo político. El mismo Rawls reconoce que Habermas, en realidad, lo cuestiona sobre el rol condicionante, en términos de reglas del discurso, de las distintas doctrinas dentro de un consenso sobrepuesto (overlaping consensus), sobre todo acerca de la justificación de la concepción política, una vez que los ciudadanos vean esta concepción como razonable e independiente. Para Rawls, el liberalismo se basa en tres tipos de justificación. Primero, una justificación pro tanto de la concepción política, donde se tiene en cuenta apenas valores políticos que pueden dar una respuesta razonable a través del uso de la razón pública. Segundo, una justificación de parte del ciudadano en la sociedad que puede sostener una determinada doctrina como comprensiva o razonable. Y tercero, la justificación pública de la concepción política en relación a la sociedad política más amplia. Por lo tanto, el principio de justificación del liberalismo político está pautado a partir de una noción político-moral de tolerancia, ya que por más razonable que un ciudadano o grupo político puedan creer que su doctrina es justificable (o más justificable que otras), siempre va a haber una instancia superior que será figurada simbólicamente a través del uso público de la razón. La razón pública funciona, así, como "un estándar para establecer los límites de la tolerancia y para evaluar las reivindicaciones conflictivas de los ciudadanos" (Werle, 2008: 72). Ese modo de ver "por la negativa" -y presuponiendo, además, lo que Rawls llama "velo de ignorancia"- cualquier doctrina comprensiva tiene dos tipos de consenso. Uno, más o menos significativo, a saber, aquél que tiene por objetivo formar un acuerdo político simple en la política cotidiana, por así decirlo; y otro, más abstracto, que es el "consenso entrecruzado razonable", y que presupone que la concepción política de justicia es elaborada como una visión independiente, sin apelar a doctrinas comprensivas. Por lo tanto, Rawls sólo sostiene su concepción de democracia con base en la idea de justificación pública, ya que los ciudadanos, cuando pueden ver la posibilidad de un consenso entrecruzado sobre la concepción política, pueden también verificar si hay razones suficientes para proponer la justicia como equidad sin rechazar los compromisos con las doctrinas que se pretenden amplias y comprensivas. Para Rawls, Habermas pretende tener una de esas doctrinas amplias y comprensivas porque la teoría de la acción comunicativa, que fundamenta el principio del discurso, pretende ser una justificación epistemológica para la democracia. 
Habermas, a su vez, critica el modelo de Rawls por su ambigüedad en ser un modelo teóricocognitivo o simplemente una elaboración político-discursiva. En este sentido, podemos decir que Habermas tiene un concepto fuerte de democracia porque el procedimiento de validación de los discursos está en el mismo nivel de los derechos fundamentales y constitucionales. Rawls, a su vez, tiene un concepto débil de democracia, por así decirlo, ya que su horizonte de aplicación no visa modificar o cuestionar la institucionalidad idealizada de la posición original. Para Habermas, los derechos liberales de los modernos tienen características a priori que rebajan el proceso democrático-deliberativo a un estatus inferior. Si tuviéramos que resignarnos al modelo de Rawls, no nos quedaría más que un acto de fe en la razón, en lo que podríamos considerar "razonable" en el marco de una constitución inamovible. Para Habermas, la concepción de justicia de Rawls basada en el hecho de que "la autonomía de los ciudadanos se constituye a través de derechos" no es capaz de dar cuenta del paradigma de la distribución y de la instrumentalización del derecho que sustrae derechos potenciales y legitima así desigualdades sociales (Habermas, 2010: 48). En el modelo rawlsiano, los derechos parecen, por el "decisionismo" del modelo de la "posición original", dejarse disfrutar tan solo en la medida que se ejercen. "No se pueden asimilar a bienes distributivos sin perder al tiempo su sentido deontológico" (ïdem). Rawls se ve forzado a considerar los derechos básicos no como un marco que regule las relaciones entre los actores, sino como "cosas" que deben ser poseídas, es decir, como bienes básicos. Recordemos que Rawls admite que su concepción de justicia no es metafísica, sino política, lo que lo hace asumir inevitablemente un sentido deontológico. "La idea es que, en una democracia constitucional, la concepción pública de la justicia debería ser independiente de doctrinas religiosas y filosóficas sujetas a controversias" (Rawls, 2000: 202). Para Habermas, el presupuesto de una "democracia constitucional" no significa que las leyes que las constituyen estén estancadas en su significación, sino que el principio de democracia, apoyado en su constitucionalidad, implica que el derecho está siempre en movimiento para atender a las demandas sociales concretas de la esfera pública y de los debates entre legisladores. No hay ningún derecho legítimo sin la legislación democrática común de ciudadanos legitimados para participar como libres e iguales en dicho proceso. Según Habermas, el autor de Teoría de la justicia presupone que "el acto de fundación del Estado de derecho democrático no puede ni precisa repetirse bajo las condiciones de una sociedad ya ordenada de modo justo" (2010: 67). Eso conlleva que el proceso de realización de los derechos no pueda ni precise ser cuestionado a largo plazo. Eso excluye, desde luego, las cambiantes condiciones históricas entendidas como un proceso abierto e inconcluso. En el modelo de Rawls, los ciudadanos "no pueden reiniciar la ignición del núcleo radical democrático de la posición originaria en la vida real de su sociedad, pues desde su perspectiva 
todos los discursos de legitimación esenciales han tenido lugar en el seno de la teoría; y los resultados de los debates teóricos se encuentran ya sedimentados en la constitución" (Habermas, 2010: 67). El modelo de Rawls, por tanto, a pesar de tener en cuenta cierto pluralismo político y, así, la tolerancia en un horizonte normativo para el entendimiento, carece de un principio democrático esencial, que es la legislación y la posibilidad de cambiar las leyes a partir de los procedimientos e, inclusive, a partir de los debates en torno a los propios procedimientos.

¿Sería el contexto democrático de aplicación del discurso la una posibilidad de una transformación justa o emancipadora? Para el Habermas de Teoría y praxis (2013), en la Francia revolucionaria, la Declaración de los Derechos del Hombre sirvió de base para una nueva Constitución; en Estados Unidos, la Declaración fue la fundamentación de la Independencia, acto político que también generó una nueva Constitución. Sin embargo, en Francia la Declaración tenía que transformar la esfera pública sobre la nueva condición universalista de la política, mientras que, en Estados Unidos, la Declaración no se debía a la necesidad de fundar una nueva cultura política cuyo principio fuera la igualdad jurídica, sino que era, más bien, una cristalización jurídica basada en una opinión pública en buena medida ya formada. Ya en Facticidad y validez, Habermas (1998) encontró un término medio entre el constitucionalismo norteamericano y el republicanismo francés. La reconstrucción que busca Habermas casi treinta años después se basa en la interdependencia de los modelos liberal y republicano. Los derechos humanos del modelo de legitimidad liberal son cooriginarios de la noción de soberanía popular del modelo republicano. A Habermas le interesa la validez de la forma lingüística del derecho. "La fuente de toda legitimidad radica en el proceso democrático de producción del derecho, y ese proceso apela a su vez al principio de soberanía popular" (Habermas, 1998: 155). La pregunta por esa "validez", a su vez, busca el principio de justificación de legitimación desde el principio del discurso hacia el lenguaje institucionalizado del derecho.

El principio de la soberanía popular se expresa en los derechos de comunicación y participación que aseguran la autonomía pública de los ciudadanos; el imperio de la ley, por su parte, en aquellos clásicos derechos fundamentales que garantizan la autonomía privada de los ciudadanos (Habermas, 1999: 252).

Habermas busca, de este modo, una dimensión práctico-emancipadora de la democracia al sostener que los derechos humanos no actúan sólo externamente como normas morales, sino principalmente como reglas formales de procedimiento de la legislación y control institucional. 
Habermas defiende la tesis de que una cooriginalidad entre derechos humanos y democracia es la base de "un modelo deliberativo de formación democrática de la opinión y la voluntad" (Lohmann, 2013: 98). El filósofo alemán quiere conciliar, por lo tanto, la matriz liberal y la matriz republicana. Contra una interpretación liberal, Habermas busca apoyarse en una interpretación republicana del lenguaje jurídico y constitucional. Y contra el republicanismo comunitarista, desarrolla un consecuente entendimiento procedimentalista constitucional.

A lo largo de sus elaboraciones teóricas, Habermas busca un modelo reconstructivo más sólido para pensar la relación entre democracia y derechos humanos. No significa apenas, como quería Rorty (1990), un diálogo crítico con las ideas del pasado a la luz del presente, sino también una reelaboración teórica que busca justificarse en la praxis, es decir, que busca una proyección performativa hacia un nuevo contexto de aplicación. Para Habermas, "reconstruir" es un modo específico de validación de la teoría a través del cual se pueden anclar en la realidad de las sociedades capitalistas avanzadas los potenciales emancipadores. Éstos serían la posibilidad real del contenido normativo propio de los criterios que orientan la crítica de la sociedad y de las demás teorías atravesadas por la sociedad (Nobre y Repa, 2012: 18). "En la medida en que las reconstrucciones racionales hacen que las diferenciaciones entre las pretensiones de validez trasciendan las fronteras tradicionales, pueden determinar nuevas pautas analíticas y adoptar en consecuencia una función reconstructiva" (Habermas, 2008: 42). La preocupación de Habermas se centra en la producción de conocimientos que, pese a su falibilidad, sean capaces de sostener, de algún modo, la plausibilidad de la reconstrucción de las estructuras normativas profundas. La teoría crítica debería, por así decirlo, perder su característica parasitaria de otras ciencias, como se puede pensar en la oposición teoría tradicional/teoría crítica propuesto inicialmente por Horkheimer. Antes que limitarse a interpretar críticamente otras teorías y su aplicabilidad, las ciencias sociales deberían producir "conocimientos teóricos" (Habermas, 2008: 43). Los principios de justificación como el principio del discurso o el principio democrático son un ejemplo de esa elaboración teórica. La reconstrucción permite vislumbrar, en la posibilidad de aplicación de las teorías, cuáles son los potenciales constructivos inseridos en determinadas estructuras ya alcanzadas que aún no fueron desarrolladas de modo suficiente en la sociedad (Nobre y Repa, 2012: 18). Como principio de justificación, el principio de democracia se basa en el sentido realizativo de la práctica de la autodeterminación de los miembros de una comunidad jurídica. El principio democrático, por lo tanto, tiene por finalidad fijar -y legitimar- un procedimiento de producción legítima de normas jurídicas. El procedimiento democrático "institucionaliza formas de comunicación necesarias para la formación racional de la voluntad" (Habermas, 1998: 248). 


\section{Justificación y derechos humanos}

La reconstrucción teórica de Rainer Forst está atravesada por tres autores contemporáneos: John Rawls, Habermas y Axel Honneth. A partir de la noción de moral de la teoría del reconocimiento de Honneth, Forst propone que el constructivismo fundado en la noción de justificación se compone de la articulación entre el constructivismo moral y el constructivismo político. Siguiendo a Habermas, Forst explica que esa articulación debe ser discursiva, es decir, ambos constructivismos tienen una pretensión de validez social que, cuando una persona moral necesita ser entendida, se libera de su contexto meramente "local" y busca crear normativamente interlocutores de otros ámbitos sociales, esferas de validez del discurso o mismo "culturas", aunque este concepto genere malentendidos esencialistas. Esa búsqueda reflexiva por validez significa que "no hay razones morales significantes que hablen contra la corrección de la norma" (Forst, 2005: 41). Por un lado, Forst está de acuerdo con Habermas cuando éste argumenta en favor de una cooriginalidad de los derechos humanos y la soberanía popular: en el estado democrático de derecho los ciudadanos son tanto sujetos de la justificación política, o sea, ciudadanos, como sujetos de la ley, o en otras palabras, personas jurídicas (Forst, 2005: 50). Eso quiere decir que las normas constitucionales son modificables. Para Habermas, el principio de la soberanía popular consolida un procedimiento que fundamenta la expectativa de resultados legítimos con base en sus cualidades democráticas. Aquí el énfasis habermasiano está puesto en el principio que garantiza el "derecho a la comunicación" y a la participación que le aseguran al ciudadano su "autonomía pública" (Habermas, 2001: 146). Los derechos humanos son para Habermas derechos vinculados a la libertad privada, es decir, a los ámbitos de acción que tienen las personas para realizar sus planes de vida. Son esos derechos los que fundamentan una soberanía legítima de las leyes. Así, Habermas sostiene que hay un nexo interno entre los derechos humanos y la soberanía popular, que consiste en el hecho de que los derechos humanos institucionalizan las condiciones de comunicación para la "formación de la voluntad política racional" (Habermas, 2001: 148). Las autonomías privada y pública se presuponen recíprocamente. En su teoría política deliberativa que intenta reconciliar el liberalismo y el republicanismo, Habermas explica que ese nexo interno entre democracia y estado de derecho consiste en que los ciudadanos tienen que ser independientes, tanto en su autonomía privada -asegurada de modo igualitario-, cuanto independientes en su autonomía pública (Habermas 2001: 149).

Sin embargo, Forst tiene una perspectiva muy distinta a la de Habermas, al mostrar que las porosidades que unen y a la vez separan tanto el principio liberal (autonomía privada), como el 
principio republicano (autonomía pública) se dan de modos muy diversos en situaciones concretas. Esa diversidad es lo que hace que Forst retome de Honneth el sentido moral de los conflictos por el reconocimiento, ya que la justificación es una articulación necesariamente moral y política a la vez. Para Forst, los derechos humanos son también construcciones jurídicas situables. Tienen su forma concreta en su sentido legal positivo y pueden ser mejorados, revitalizados y reivindicados a partir de los procedimientos del estado de derecho, pero, a su vez, esos derechos también son morales, pues son capaces de crear una neutralidad objetiva que abarque la comunidad moral de modo abstracto y, por lo tanto, también son políticos: el derecho a la justificación como principio de los derechos humanos, en su situación concreta, revela las condiciones normativas y conflictivas de su legitimidad. Esa elaboración de "comunidades de justificación" (moral, política, ética, etcétera) no se restringe a las fronteras nacionales. La articulación entre el constructivismo moral y el político permite una horizontalidad de los derechos justificados: "El derecho a la justificación no sólo impone condiciones internas a la soberanía política, sino que también establece límites a la conducta externa" (Forst, 2005: 52). Así, si las intervenciones externas tienen prioritariamente el sentido de prevenir situaciones de violación sistemática y duradera de los derechos humanos, ellas mismas están sometidas a una estricta obligación de justificación. "La pretensión de establecer la paz es sólo un paso en el camino para restablecer una situación en la que los ciudadanos puedan ejercer su derecho a la justificación en su propia comunidad política" (Ibídem: 55).

Siguiendo ahora a John Rawls, Forst distingue comunidad moral (o ética) de comunidad política: "mientras que la comunidad política es integrada normativamente por medio de una concepción política y pública de la justicia, las comunidades éticas se integran por medio de diferentes tipos de concepción del bien" (Ibídem: 39), es decir, doctrinas morales y éticas abarcadoras. De esta distinción deriva otra, fundamental para el pensamiento rawlsiano, entre "racional" y "razonable". El concepto de racional remite a la capacidad de formular y perseguir una concepción del bien, mientras que el concepto de razonable corresponde a la capacidad para generar consensos posibles de justicia (Ibídem: 35). Sin embargo, el argumento de Forst difiere del de Rawls: Forst no separa de modo necesario el constructivismo moral, es decir, la búsqueda colectiva orientada hacia una noción de bien ética, del constructivismo político donde predomina lo público. Para Forst esos dos constructivismos deben estar articulados porque esa articulación es la base discursiva de la justificación. Esto quiere decir que Forst no está interesado en "relativizar" la justificación. Sería una importante pérdida teórica suponer una justificación moral separada y totalmente independiente de una justificación pública o política. El derecho a la justificación debe presuponer la articulación de ambas esferas, ya que ésta es la base de un discernimiento capaz de medir y situarse en la formación de marcos sociales y 
conflictivos en formación. Así, en esa necesidad de situarse en comunidades políticas es posible afirmar que el derecho a la justificación, como resultado de un constructivismo también moral, incluye potencialmente a toda la comunidad moral, es decir, a todos los seres humanos (Forst, 2005: 45).

Esta articulación le permite a Forst desarrollar una crítica que es inmanente y trascendente a la vez, dado que está basada en una dialéctica entre diversos marcos y niveles de "lo local" y "lo general" como norma de universalidad y reciprocidad. Es en la construcción de una "neutralidad moral" que las justificaciones demandan su validez, pero únicamente situadas en demandas concretas y con interlocutores determinados. Si se tiene en cuenta la tesis de Rawls de "la justicia como equidad", sería injusto y parcial que un autor de ciertas demandas éticomorales o jurídicas pretendiese derechos y privilegios que él niega a otros potenciales destinatarios de esas pretensiones, o que pretendiese imponer sus opiniones (Forst, 2005: 40). Así, es fundamental en una reivindicación la reciprocidad moral y política de los diversos actores sociales involucrados. La universalidad es otro criterio primordial, ya que aparece como contraposición a "lo local", es decir, como contrapunto de lo contextual. La universalidad es una proyección moral trascendente y, de este modo, base normativa para los derechos humanos. Sin embargo, esa universalidad se articula discursivamente en un contexto moral donde "no debe restringirse la comunidad de justificación de manera arbitraria, sino que debe incluir a todos aquellos afectados por las acciones o las normas en una forma moral relevante" (Ibídem: 40). Para Forst, por lo tanto, ninguna cultura o comunidad ética puede negar la posibilidad de esa neutralidad -articulada de modo constructivo- como un mero "descubrimiento" externo, "puesto que su propia pretensión a la integridad cultural y a la aceptación interna presupone la afirmación del derecho a la justificación" (Ibídem: 43). Lo que el autor alemán llama "derecho básico a la justificación" debe ser entendido como una construcción discursiva reflexiva entre distintos ámbitos de validez, teniendo en cuenta una articulación entre los niveles de pretensión de validez del discurso más "locales" y los niveles de pretensión de validez más generales. Cuanto más se debe recurrir a las esferas "locales" de validez, más se debe tener en cuenta los criterios de reciprocidad, lo que permitirá revelar cómo la reciprocidad está dañada en las estructuras sociales locales. Al ampliar el foco a percepciones más "generales", esas distorsiones también se hacen notar como síntomas de una estructura que trasciende el nivel inmediatamente local o que hacen notar especialmente un caso como aberrante y desviado de cualquier expectativa. Sin embargo, las pretensiones normativas de universalidad sirven, como último nivel de validez, para establecer niveles de crítica y comparación.

En Habermas, Honneth y Forst, la reconstrucción racional aparece como un procedimiento metodológico para justificar la normatividad de ciertos parámetros de la crítica. Habermas 
reconstruye el vínculo entre principio del discurso y principio de democracia, además de la cooriginalidad entre derechos humanos y soberanía popular como condición de posibilidad para una democracia deliberativa, mientras que para Honneth, las esferas de reconocimiento son reconstrucciones normativas de ciertos ámbitos de validez y sus patologías que buscaban parámetros de evolución (o regresión) social en la modernidad. En Rainer Forst, a su vez, los derechos humanos en su horizonte de aplicación deben ser encarados desde una articulación entre constructivismo moral y constructivismo político. El constructivismo moral, como aparece en Rawls, "es una parte, más que una alternativa al constructivismo político" (Forst, 2005: 45). El constructivismo moral se limita a, en el mejor de los casos, establecer una "lista de derechos humanos". El constructivismo político, por su lado, entabla "ideas específicas relacionadas con el contexto de la estructura básica de una sociedad" (Forst, 2005: 45). Si Rawls (1993) intenta establecer una fundamentación de los derechos humanos y de la justicia internacional que trascienda las culturas en términos universalistas, el "constructivismo diferenciador" que propone Forst se constituye a partir del derecho a la justificación y los criterios de responsabilidad y universalidad. Este constructivismo diferenciador -o discursivo- "conduce a una justificación moral más directa y fuerte de los derechos humanos y de la justicia internacional" (Forst, 2005: 45). Si para Habermas el principio de justificación para la democracia es el principio del discurso, y para Honneth el principio de justificación es el reconocimiento y el derecho a la libertad, para Forst el principio de justificación es el derecho a la justificación, es decir, poner en juego una "concepción razonable de justificación" "en los distintos contextos en los cuales los miembros de diferentes comunidades tienen que encontrar y aceptar los principios que deben guiar su vida colectiva" (Ídem). Antes que una pretensión de universalizar la validez epistemológica de la democracia, como quiere Habermas, o de encontrar parámetros normativos para pensar las patologías en las esferas de reconocimiento, Forst busca un principio de justificación que parta de una construcción situada en el marco de la aplicabilidad concreta de los derechos humanos. El contexto de aplicación en Habermas y Honneth se limita a las sociedades occidentales desarrolladas y marcadas con el signo de una modernidad cultural. Para Forst, los distintos universos locales exigen también otros principios normativos que deben ser reconstruidos desde distintos niveles -mundos de la vida, sistemas, esferas- cada vez que se pretende abstraer la entidad moral unificadora de los derechos humanos. Por su pretensión siempre abarcadora, "las normas morales tienen que ser justificadas en la comunidad moral de todos los seres humanos, mientras que las normas de la justicia social y política deben ser justificadas en las comunidades políticas particulares" (Forst, 2005: 45). 
La teoría constructivista de Forst busca reconstruir las "experiencias morales y los procesos de aprendizaje de los seres humanos que proveen argumentos para los derechos humanos que no pueden ser negados universal y recíprocamente" (Ibídem: 46). Eso significa que, pese a su necesaria normatividad moral e inclusive jurídica (justicia internacional), los derechos humanos no dependen de ninguna "fundamentación última, sino que tales derechos representan el resultado de desarrollos normativos históricos relevantes" (Ídem). Esa concepción de derechos humanos debe estar abierta, así, a otras argumentaciones, sin que por eso tenga un débil contenido moral. Esa concepción de derechos humanos no está basada en verdades platónicas, sino en criterios para validar los discursos de esos derechos. Así, cada construcción de una lista de derechos humanos deja de ser considerada una Creatio ex nihilo: lo que resalta Forst es que cada lista de derechos humanos tiene necesariamente un carácter provisional y situable, y puede ser cuestionada gracias al derecho a la justificación ya que es "el resultado de experiencias históricas y procesos de aprendizaje" (Forst, 2005: 46). Una lista de derechos humanos que presentara una normativa a priori sería meramente utópico-política porque su contenido moral se estaría siempre redibujando en nuevos fundamentos, acuerdos y principios. Aquí podríamos pensar en el modelo dialéctico de Koselleck (2006) que propone una articulación entre espacio de experiencia y horizonte de expectativa. El espacio de experiencia -a partir de la construcción política de los derechos humanos- proyecta en la percepción de tiempo, un horizonte de expectativas, una democracia más sólida y permite vislumbrar de modo más crítico las aberraciones del pasado. La justificación para los derechos humanos está por lo tanto siempre en movimiento. En este sentido, Forst defiende la necesidad de considerar el constructivismo moral necesariamente articulado al constructivismo político: "la justificación moral es -en un sentido formal normativo- el núcleo de la justificación política" (Forst, 2005: 47). En su universalismo contextualista, Forst sostiene que "los derechos humanos son demandados en ciertas situaciones políticas donde las relaciones sociales se examinan en relación con su [propia] legitimidad" (Ídem) y donde esos derechos como pretensiones no rechazables están amenazados o no se cumplen. Por lo tanto, las demandas de derechos humanos actúan en contextos concretos y son ellas mismas elaboradas discursivamente con contenidos concretos que anhelan corregir anomalías del poder social y político de una determinada comunidad política.

\section{Notas conclusivas: dos variaciones sobre el constructivismo moral y político de los derechos humanos}


Vimos con Habermas que la democracia tiene resortes normativos, es decir, inmanentes a la sociedad y, por otro, elementos formales legitimados política y jurídicamente. La justificación de la democracia es discursiva y no meramente formalista, lo que le abre espacio a la dimensión política. Que sea discursiva no excluye la política y la metapolítica como horizonte metadiscursivo, lo que aleja a Habermas del liberalismo de Rawls y del contextualismo de Rorty. Y vimos con Rainer Forst una teoría constructivista de los derechos humanos que busca articular el constructivismo moral con el constructivismo político. Siguiendo a Habermas y Forst, Christoph Menke y Arnd Pollmann (2010) plantean un abordaje a los derechos humanos teniendo en cuenta algunas controversias de su elaboración y aplicación de las cuales destacaremos dos. Esa articulación nos evita el problema de determinar si los derechos humanos son fruto exclusivo de una "universalidad ideal" o de una positivación jurídica desde el Estado. Más bien consideramos con Habermas que hay una cooriginalidad entre el aspecto jurídico fundamental y la legitimación. Sin embargo, eso parece no resolver definitivamente la primera controversia, aquella entre la concepción moral y la concepción política de los derechos humanos. A favor de la concepción moral se puede argumentar que ella explicita el contenido conceptual de los derechos humanos, ya que los concibe en el sentido de una validez preestatal. Siguiendo un punto de vista deontológico, esta concepción sostiene que, ante el orden político, sólo un argumento teorético-moral puede formular un motivo por el que cada hombre realmente debe ser tratado como igual y ser considerado legalmente. Esto se debe a que todos los hombres estarían comprometidos con eso y lo están tanto de un "modo recíproco y categórico" como de un modo político, es decir, como "representantes de un orden político" (Menke y Pollmann, 2010: 74). Además, la concepción moral de los derechos humanos no tiene que dar por sentada -ni empírica ni conceptualmente- la existencia de comunidades políticas con o $\sin$ democracia. Buscando un criterio no necesariamente "autónomo" en relación a la política, la concepción moral puede constatar de forma distanciada "la validez [o no] de los derechos humanos allí donde las comunidades políticas no son democráticas, no se basan en el Estado de derecho, son frágiles o se han desintegrado" (Menke y Pollmann, 2010: 75). Por lo tanto, la concepción moral logra formular una justificación "a tener derechos", en el sentido de Hannah Arendt, y a poner límites a los colectivos que se autogobiernan inclusive democráticamente.

Por otro lado, en favor de la concepción política se puede sostener que el contenido de los derechos humanos es un orden público en el que todos los hombres son considerados como iguales. Es a través de la política que los derechos humanos pueden reivindicar ciertas condiciones, siempre situadas en problemas concretos. Para Honneth (2014) las esferas del reconocimiento tienen una dimensión moral. Sin embargo, el derecho a la libertad como 
fundamento de una eticidad democrática activa el sentido colectivo del "derecho a tener derechos". El principio de justificación tanto discursivo -como en Habermas- como en relación al reconocimiento sólo se articula en realidades situadas. Lo moral, en su aspecto críticocognitivo de una situación de desacato a los derechos humanos, no puede excluirse de una situación política concreta: los ideales reguladores de esa idea moral suprema deben asumir formas y actitudes precisas en la realidad posible de cada caso. Antes que pensar en el modelo de la "libertad de los antiguos", donde los derechos y la legitimidad son determinados por "la mayoría", la concepción política debe tener en cuenta la dimensión moral de los derechos humanos justamente para poder recibir las demandas de las minorías afectadas o invisibilizadas. Para Rainer Forst, el fundamento de los derechos humanos es la capacidad de reconocer a cada hombre como una persona moral, y la disposición política a hacerlo. En la tensión dialéctica entre la concepción moral y la concepción política, podríamos concluir que los derechos humanos deben ser construidos políticamente, pero justificados moralmente.

La segunda controversia se refiere a la tensión entre un universalismo minimalista y otro maximalista, por así decirlo. La cuestión en juego enfoca "cuán extensamente se puede determinar el contenido [y el alcance efectivo] de los derechos humanos" (Menke y Pollmann, 2010: 136). La comprensión maximalista de los derechos humanos se basa en un concepto de "hombre" que incluye a todas las culturas según "propiedades y necesidades humanas generales, las cuales pueden ser vulneradas" (Ídem). Según la concepción maximalista, los derechos humanos son "indivisibles". Los planteos minimalistas basados en los clásicos derechos liberales no entienden la profundidad de los reglamentos:

incluso cuando 'sólo' deben garantizar la integridad corporal, al mismo tiempo deben exigir todo lo que es necesario para el mantenimiento y el reconocimiento del correspondiente orden público, como por ejemplo derechos a la participación política y, a su vez, para garantizar estos últimos, derechos a la participación social y cultural (Menke y Pollmann, 2010: 137).

Al limitar los derechos a unos pocos contenidos casi siempre abstractos, como queda explícito en la concepción minimalista, se ignora las enseñanzas del desarrollo histórico de los derechos humanos, ya que para lograr concebir y aplicar un sistema de derechos de esa magnitud es necesario presuponer que hubo que partir de derechos más básicos. La objeción minimalista, por su parte, sostiene que el maximalismo, en su ambición de vincular todos los derechos, pasa por encima tanto de la especificidad concreta de cada caso, como de la dimensión propiamente universal de los derechos humanos. Para la objeción minimalista, "Ios derechos 
humanos sólo tienen una oportunidad para hacer justicia al hecho del pluralismo formado por distintas culturas si limitan su alcance consecuentemente a un mínimo" de normas (Menke y Pollmann, 2010: 137). La concepción maximalista, al intentar basarse en una amplia reconstrucción de derechos, perdería de vista el universalismo, lo que lo vaciaría de contenido. "El maximalismo de su contenido y el universalismo de su validez se excluyen mutuamente" (Ídem). Vimos con Forst que el derecho a la justificación es una articulación entre el constructivismo moral, es decir, lo que puede ser "razonable" justificadamente ("no hay razones morales significantes que hablen contra la corrección de la norma") en el sentido de Rawls, y el constructivismo político, lo que puede ser instaurado a partir del discurso y su potencial emancipador en el procedimentalismo democrático, como quiere Habermas. La concepción minimalista se refiere al constructivismo moral porque no combate el hecho de que es deseable un contenido exigente de los derechos humanos, sino únicamente que se puedan presentar argumentos a favor de este contenido que no sean en sí mismos particulares de una cierta cultura" (Ibídem: 137-138). La objeción minimalista no cuestiona la estrechez o amplitud del alcance de los derechos humanos, sino, antes, las posibilidades de obtener un acuerdo universal en relación con este contenido. Sin embargo, el minimalismo, lejos de rechazar una perspectiva situacionista, advierte que quien declare o reivindique los derechos humanos lo "hace de una determinada manera, en una lengua determinada y con ayuda determinada de otras ideas e ideales" (Ibídem: 138). Pero el minimalismo supone, no obstante, que hay algunos contenidos "mínimos" que están excluidos de esa regla, contenidos de validez universal indiscutible que no serían relativizables. Esa universalidad estaría garantizada por su "neutralidad". Lo que quieren mostrar Menke y Pollmann es que ambas concepciones no se excluyen entre sí, sino más bien que ambas están, al fin y al cabo, interesadas en fundamentar -como teoría y como praxis- un proceso de universalización de los derechos humanos. El maximalismo necesita basar su reconstrucción en los potenciales inmanentes a una determinada totalidad social; el minimalismo necesita construir una posición neutral mínima para poder reivindicar los derechos y fundamentos que cree justificables moralmente. Ambas concepciones se complementan.

\section{Bibliografía}

Bonjour, L. (1976). The coherence theory of empirical knowledge. Philosophical Studies, 30(1), pp. 281-312. 
Burdzinski, J. C. (2005). Justificação, coerência e circularidade. Revista Veritas, 50(4), Porto Alegre, pp. 65-93.

Forst, R. (2005). El derecho básico a la justificación: hacia una concepción constructivista de los Derechos Humanos. Estudios Políticos, Medellín, 26(1), pp. 27-59.

Forst, R. (2010). Contextos da justiça. São Paulo: Ed. Boitempo.

Habermas, J. (1999). La inclusión del otro. Estudios de teoría política. Barcelona: Ed. Paidós.

Habermas, J. (2001). A constelação pós-nacional. Ensaios políticos. São Paulo: Littera Mundi.

Habermas, J. (2006). ¿Tiene todavía alguna posibilidad la constitucionalización del derecho internacional? En El occidente escindido. Madrid: Ed. Trotta.

Habermas, J. (2008). Conciencia moral y acción comunicativa. Madrid: Ed. Trotta.

Habermas, J. (2010). Reconciliación mediante el uso público de la razón. En Habermas, J. y Rawls, J. Debate sobre el liberalismo político. Barcelona: Ed. Paidós.

Habermas, J. (2013). Teoria e praxis. São Paulo: Ed. UNESP.

Honneth, A. (2014). Derecho a la libertad. Esbozo de una eticidad democrática. Buenos Aires: Ed. Katz y Capital Intelectual.

Koselleck, R. (2006). Futuro passado. Contribuição à semântica dos tempos históricos. Rio de Janeiro: Ed. PUC do Rio.

Lohmann, G. (2013). As definições teóricas de direitos humanos de Jürgen Habermas: o princípio legal e as correções morais. Revista Transformação, Marília, 36(Ed. especial), pp. 87-102.

Menke, C. y Pollmann, A. (2010). Filosofía de los derechos humanos. Barcelona: Ed. Herder.

Rawls, J. (1993). The law of peoples. En Shute, St. y Hurley, S. On Human Rights. New York: Harper Collins Publisher.

Rawls, J. (2006). El liberalismo político. Barcelona: Ed. Crítica.

Rawls, J. (2002). Justiça e democracia. São Paulo: Ed. Martins Fontes.

Rorty, R. (1990). La historiografía de la filosofía: cuatro géneros. En Rorty, R.; Schneewind, J. B. y Skinner, Q. (org.) La filosofía en la historia. Ensayos de historiografía de la sociología. Buenos Aires: Ed. Paidós.

Rorty, R. (1996). Objetivismo, relativismo y verdad. Barcelona: Ed. Paidós.

Rorty, R. (2000). Pragmatismo, una versión. Antiautoritarismo en epistemología y ética. Lecciones en la Universidad de Girona en Julio de1996. Barcelona: Ed. Ariel.

Werle, D. L. (2008). Justiça e democracia. Ensaios sobre John Rawls e Jürgen Habermas. São Paulo: Ed. Singular e Esfera Pública. 